On the Evolution of Wage Inequality in Acemoglu's Model of Directed Technical Change

\author{
Matthias Weiss
}

99-2005 


\title{
On the Evolution of Wage Inequality in Acemoglu's Model of Directed Technical Change*
}

\author{
Matthias Weiss ${ }^{\dagger}$
}

September 2005

\begin{abstract}
In Acemoglu's model of directed technical change, the skill-premium increases in consequence of an increase in the relative supply of skilled labor. In this paper, I argue that other measures of wage inequality such as the Gini-coefficient do not necessarily rise as well. The Gini-coefficient depends positively on the skill-premium but the effect of an increase in the relative supply of skilled labor is ambiguous. A simulation of Acemoglu's model shows that the growth in the relative supply of skilled labor has led to increased wage inequality in the past but will lead to decreasing wage inequality in the future.
\end{abstract}

Keywords: Directed Technical Change, Wage Inequality

JEL Classification: J31, O33

\section{Introduction}

Rising wage inequality in the 1980s has generated a vast literature on so-called skill-biased technological change and other possible explanations. A broad consensus has emerged that skill-biased technological change has been a major cause for a shift in the relative demand for skilled labor and that this shift in demand has been a primary source of rising wage inequality. ${ }^{1}$ Regarding the longer run prospects, Murphy and Welch (2001) among others argue that rising wage inequality creates incentives for human capital investment so that "... the supply responses to the shifts in demand, that produced increasing wage inequality, will ultimately produce increasing equality..." (Page 1). This argument is questioned by Acemoglu and others who have convincingly argued that skill-biased technological change has not only been the cause for but also the consequence of increases in the relative supply of skilled labor:" "A high proportion of skilled workers in the labor force implies a large

\footnotetext{
*I am grateful to Melanie Lührmann for valuable comments and suggestions.

${ }^{\dagger}$ MEA, Universität Mannheim, L13 17, 68131 Mannheim, Germany, Tel: +49 621181 1871, E-Mail: weiss@mea.uni-mannheim.de

${ }^{1}$ See, eg, Gottschalk and Smeeding (1997), Berman, Bound, and Machin (1998), Katz and Autor (1999), and Acemoglu (2002a).

${ }^{2}$ See Acemoglu ((1998), (2002a), (2002b)) and Kiley (1999).
} 
market size for skill-complementary technologies, and encourages faster upgrading of the productivity of skilled workers." (Acemoglu (1998), page 1055). In this case, reacting to demand shifts by respective supply shifts is counterproductive and "... we can have an equilibrium path in which both the relative supply of skills and the skill premium increase together over time." (Acemoglu (2002b), page 44).

This view suggests that a growing supply of skilled labor will lead to ever rising wage inequality. In this paper, I argue, that even if the relative supply of skills and the skill premium continue to grow, wage inequality (in terms of standard inequality measures like the Gini-coefficient or the variation coefficient) will not. The reason is that even if the gap between the wages for skilled and unskilled workers continues to grow, the number of those workers who earn the low wage falls. At some point, so many workers earn the same (high) wage that the (ever increasing) gap between the high and the low wage becomes minor. ${ }^{3}$

In the next Section, I briefly present a simplified version of Acemoglu's model of directed technical change and derive the Gini-coefficient as a function of the relative supply of skills given the endogenous relative wage. In Section 3, I simulate the evolution of the Gini-coefficient for different values of the model parameters. Section 4 concludes.

\section{The Model}

Acemoglu (1998) argues that the direction of technological change can be controlled by innovators. Innovators develop new technologies that are complements to the factor that is abundant. ${ }^{4}$ In what follows, I will briefly sketch a simplified version of Acemoglu's model. ${ }^{5}$ The final consumption good is produced by many identical small firms using unskilled and skilled labor according to the following technology:

$$
Y\left(A_{l}, L, A_{h}, H\right)=A \cdot\left[\gamma \cdot\left(A_{l} \cdot L\right)^{\frac{\sigma-1}{\sigma}}+(1-\gamma) \cdot\left(A_{h} \cdot H\right)^{\frac{\sigma-1}{\sigma}}\right]^{\frac{\sigma}{2 \cdot(\sigma-1)}}
$$

where $L$ and $H$ denote employment of unskilled and skilled labor, $A_{l}$ and $A_{h}$ represent factor specific technologies, and $-\sigma$ is the elasticity of substitution between unskilled and skilled labor. Firms maximize profits choosing quantities of unskilled and skilled labor $(L$ and $H$ ) and technology $\left(A_{l}\right.$ and $\left.A_{h}\right)$. Profits are given by:

$$
\pi=Y\left(A_{l}, L, A_{h}, H\right)-w_{l} \cdot L-\frac{1}{\eta_{l}} \cdot A_{l}-w_{h} \cdot H-\frac{1}{\eta_{h}} \cdot A_{h}
$$

where $w_{l}$ and $w_{h}$ are wages for unskilled and skilled labor and $\frac{1}{\eta_{l}}$ and $\frac{1}{\eta_{h}}$ are the costs

\footnotetext{
${ }^{3}$ In the extreme case where all workers have become skilled, the wage premium may be gigantic, but it's irrelevant.

${ }^{4}$ The requirement for this result is that the elasticity of substitution between the production factors is larger than 1. In the case of unskilled vs. skilled labor, this is supported by the empirical evidence.

${ }^{5}$ For ease of presentation, I abstain from endogenous growth. The spirit of the model of directed technical change is not affected by this simplification.
} 
that arise when $A_{l}$ and $A_{h}$ are upgraded. ${ }^{6}$ First order conditions with respect to $L$ and $H$ yield the optimal factor input ratio $\frac{H}{L}=\left(\frac{1-\gamma}{\gamma}\right)^{\sigma} \cdot\left(\frac{A_{h}}{A_{l}}\right)^{\sigma-1} \cdot\left(\frac{w_{h}}{w_{l}}\right)^{-\sigma}$. With inelastic labor supplies $L$ and $H$, labor market clearing implies for the relative wage:

$$
\frac{w_{h}}{w_{l}}=\frac{1-\gamma}{\gamma} \cdot\left(\frac{A_{h}}{A_{l}}\right)^{\frac{\sigma-1}{\sigma}} \cdot\left(\frac{H}{L}\right)^{-\frac{1}{\sigma}}
$$

The relative wage for skilled labor depends negatively on the relative supply of skilled labor -if technology is exogenously given. Acemoglu calls this the substitution effect. The relative demand curve is downward sloping with elasticity $-\sigma$. But firms can choose technology in order to maximize profits. First order conditions with respect to technology choice yield

$$
\frac{A_{h}}{A_{l}}=\left(\frac{1-\gamma}{\gamma}\right)^{\sigma} \cdot\left(\frac{H}{L}\right)^{\sigma-1} \cdot\left(\frac{\eta_{h}}{\eta_{l}}\right)^{\sigma}
$$

If unskilled and skilled labor are gross substitutes $(\sigma>1)$, the optimal ratio of $A_{h}$ to $A_{l}$ is increasing in the relative supply of skilled labor. Acemoglu calls this the market size effect: As $A_{i}$ is complementary to $L_{i}$, the larger is $L_{i}$ the higher is the return from increasing $A_{i}$. Plugging the endogenously determined values for technology choice into equation (3) yields:

$$
\frac{w_{h}}{w_{l}}=\left(\frac{1-\gamma}{\gamma}\right)^{\sigma} \cdot\left(\frac{\eta_{h}}{\eta_{l}}\right)^{\sigma-1} \cdot\left(\frac{H}{L}\right)^{\sigma-2}
$$

If $\sigma>2$, the market size effect outweighs the substitution effect and an increase in the relative number of skilled workers leads - via induced skill-biased technological change - to an increase in the relative wage for skilled labor. This result corresponds to equation (15) in Acemoglu (1998) and equation (22) in Acemoglu (2002a) with $\beta=1$. A special case of this result is in Acemoglu (2002b), page 33, with $\eta_{l}=\eta_{h}$ and $\gamma=\frac{1}{2}$. In this simple setting with only two types of workers, the Gini-coefficient is given by $G=\frac{\frac{H}{L}}{1+\frac{H}{L}} \cdot \frac{\frac{w_{h}}{w_{l}}-1}{\frac{w_{h}}{w_{l}} \cdot \frac{H}{L}+1}$. The evolution of the Gini-coefficient depends on two things: Changes in the earnings gap between the rich and the poor ( $\frac{w_{h}}{w_{l}}$ in this setting) and changes in the relative numbers of rich and poor $\left(\frac{H}{L}\right)$. If, as in most of the literature on skill-biased technological change and wage inequality, only the skill-premium is considered, the "composition effect" of $\frac{H}{L}$ is neglected. This is innocent if the skill composition is constant. But in a context where the evolution of the skill composition constitutes an integral part of the story, this composition effect becomes important.

With the relative wage given by equation (5), the relative supply of skilled labor affects the Gini-coefficient directly (composition effect) and indirectly via changes in the relative wage ("gap effect"):

$$
G=\frac{\frac{H}{L}}{1+\frac{H}{L}} \cdot \frac{\left(\frac{1-\gamma}{\gamma}\right)^{\sigma} \cdot\left(\frac{\eta_{h}}{\eta_{l}}\right)^{\sigma-1} \cdot\left(\frac{H}{L}\right)^{\sigma-2}-1}{\left(\frac{1-\gamma}{\gamma}\right)^{\sigma} \cdot\left(\frac{\eta_{h}}{\eta_{l}}\right)^{\sigma-1} \cdot\left(\frac{H}{L}\right)^{\sigma-1}+1} .
$$

\footnotetext{
${ }^{6}$ In this model, $A_{l}$ and $A_{h}$ are just two factor inputs that are chosen such that marginal productivity equals marginal cost.
} 
This equation determines a hump-shaped relation between the Gini-coefficient $G$ and the relative supply of skilled labor $\frac{H}{L}$. Starting from very low values of $\frac{H}{L}$, an increase in $\frac{H}{L}$ implies an increase in the Gini-coefficient for two reasons: In a situation with many poor and few rich workers, inequality is rather low, because almost all (except some very few) earn the same wage. In this situation, an increase in the number of rich leads to an increase in inequality at any given gap between high and low wages because the number of workers who earn the same wage decreases (composition effect). In addition-and this is the second reason - the wage ratio is endogenous and increases with the relative number of high-skilled workers. This further boosts inequality (gap effect). But with an increasing number of skilled workers, the composition effect changes sign at some point. When there are many more rich than poor workers, an increase in the number of the rich leads to falling inequality (at any given wage ratio) because the number of workers who earn the same wage increases. With increasing $\frac{H}{L}$, the composition effect becomes stronger and at some point, it outweighs the gap effect of the increasing skill premium.

The interesting question is now, at what point the Gini-coefficient ceases to increase and starts falling again. In the following section, I simulate the evolution of the Ginicoefficient with empirically founded values for the parameters in equation (6).

\section{The Evolution of the Gini-coefficient}

The most obvious way to choose the parameter values is to estimate equation (5). Using yearly data from the US Census, this simple equation yields: ${ }^{7}$

$$
\frac{w_{H}}{w_{L}}=1.698 \cdot\left(\frac{H}{L}\right)^{0.1564} .
$$

This result corroborates Acemoglu's model: An increase in the relative number of skilled workers is associated with an increase in the relative wage for skilled labor. The implied substitution elasticity between unskilled and skilled labor is $\sigma=0.1564+2=2.1564$. Identifying $\gamma, \beta$, and $\eta$ separately is not necessary, because in the equation for the Ginicoefficient, they appear in exactly the same combination as in equation (5). The Ginicoefficient as a function of relative employment of skilled labor $\frac{H}{L}$ is given by $G=\frac{\frac{H}{L}}{1+\frac{H}{L}}$. $\frac{1.698 \cdot\left(\frac{H}{L}\right)^{0.1564}-1}{1.698 \cdot\left(\frac{H}{L}\right)^{1.1564}+1}$. Between 1975 and 2001, the relative number of skilled workers has risen from 0.51 to 1.35 . Figure 1 illustrates the evolution of the Gini-coefficient for values of relative employment of skilled labor between 0.4 and 2. The Gini-coefficient rises up to a value of 1.3 of relative skilled employment. This is roughly today's value in the U.S. If the relative number of skilled workers rises further (and if the relative wage adjusts according to Acemoglu's model), the Gini-coefficient will decrease, ie, inequality will not rise further but decrease despite the further rise in the skill-premium. This is because ever fewer workers suffer from low wages for unskilled labor and increasingly many workers

\footnotetext{
${ }^{7}$ See also Table 1 , column $(0)$.
} 
Table 1: Regression Results

\begin{tabular}{l|ccc|c}
\hline Dependent variable: log relative wage for skilled labor \\
\hline \multirow{4}{*}{ variants } & \multicolumn{3}{|c|}{ in levels } & in first differences \\
\hline constant & $(0)$ & $(\mathrm{i})$ & $(\mathrm{ii})$ & $(\mathrm{iii})$ \\
\hline & 0.530 & 0.571 & 0.578 & - \\
log relative skilled employment & $(106.9)$ & $(113.2)$ & $(60.0)$ & \\
& 0.156 & - & -0.026 & -0.105 \\
log rel. skilled emp. 7 years lag & $(11.28)$ & & $(-0.78)$ & $(-1.40)$ \\
$R^{2}$ & - & 0.135 & 0.158 & 0.206 \\
\# observations & 0.836 & 0.858 & 0.863 & 0.351 \\
& 27 & 20 & 20 & 19
\end{tabular}

Source: US Census 1975 - 2001. Unskilled: highschool and less, skilled: college and more. $t$-statistics in parentheses.

enjoy the high wages for skilled labor. So, up to now, both, the skill-premium and the Gini-coefficient for labor income have risen, but, if Acemoglu's model is taken seriously, further skill-biased technological change triggered by further growth in the relative supply of skilled labor will not lead to higher inequality in labor incomes. On the contrary, inequality will begin to fall.

Figure 1: The Evolution of the Gini-coefficient

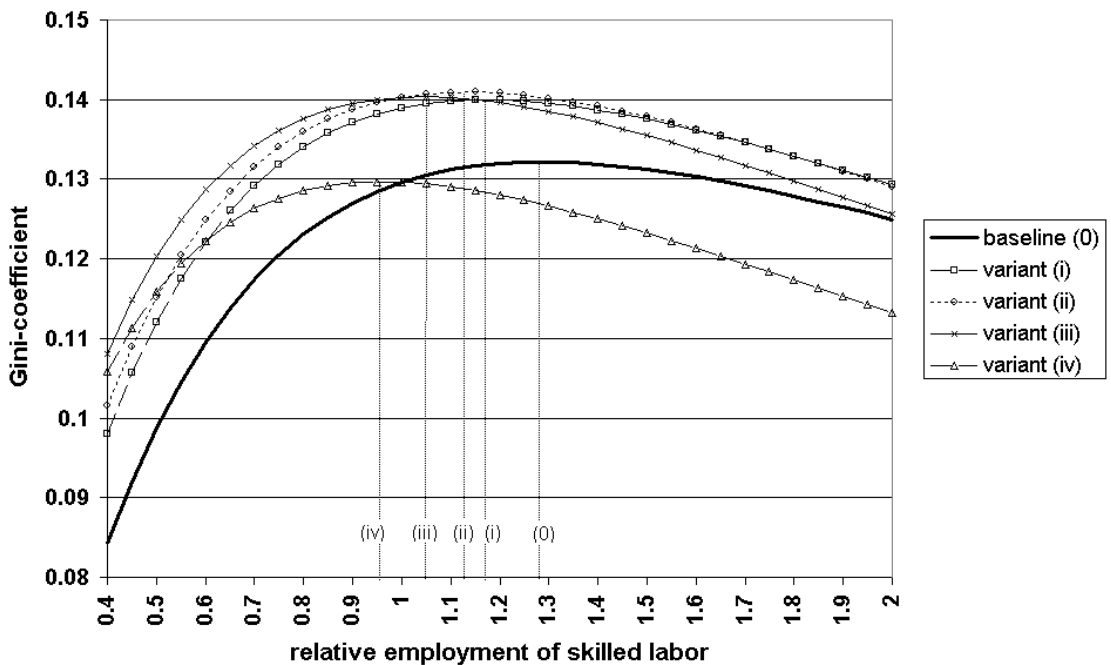

I also explored the robustness of the above result using four alternative specifications: (i) As it takes time for innovations to react to changes in the relative supply of skills, I used the lagged instead of the contemporaneous value of $\frac{H}{L}$ in the estimation. ${ }^{8}$ (ii) Because the "substitution effect" might be more immediate than the "market size effect", I included contemporaneous as well as lagged values of $\frac{H}{L}$ in the regression. As predicted

\footnotetext{
${ }^{8} \mathrm{I}$ tried 5-year, 6-year, and 7-year lags. The results are similar. Results with 7-year lags are reported.
} 
by Acemoglu's model, the substitution effect is estimated to be negative while the market size effect turns out positive. (iii) In order to avoid problems of spurious correlation, I reran the regression in first differences. In this specification the term $\left(\frac{1-\gamma}{\gamma}\right)^{\sigma} \cdot\left(\frac{\eta_{h}}{\eta_{l}}\right)^{\sigma-1}$ is not identified because it cancels out when taking first differences. So I used the constant from the specification in levels. (iv) Finally, I also used the parameter values proposed by Acemoglu (1998), page 1073/1074..$^{9}$ The regression results are in Table 1 (columns (i), (ii), and (iii)). The resulting evolution of the Gini-coefficient that is implied by these different specifications is displayed in Figure 1 (variants (i) through (iv)). The lines are not too dissimilar and imply even earlier "turning points". ${ }^{10}$ This confirms the robustness of the result with respect to different parameter values.

\section{Conclusion}

In this paper, I contribute to the debate on the effects of skills supply on wage inequality. With exogenous technology, an increase in the relative supply of skilled workers, leads to a decrease in the skill premium and falling wage inequality. ${ }^{11}$ But Acemoglu (1998) convincingly argued that the choice of technology is endogenous: A larger supply of skilled workers enhances the profitability of innovations that complement skills and therefore triggers skill-biased technological change. It has been concluded that this argument implies rising wage inequality in reaction to a rise in the relative supply of skilled workers. ${ }^{12}$ As further growth in the skilled work force is to be expected, wage inequality would be expected to grow. I argue in this paper, that this conclusion is premature. Even if the relative supply of skills and the skill premium continue to grow, wage inequality (in terms of standard inequality measures like the Gini-coefficient or the variation coefficient) does not. The reason is that even if the gap between the wages for skilled and unskilled workers continues to grow, the number of those workers who earn the low wage falls. At some point, so many workers earn the same (high) wage that the (ever increasing) gap between the high and the low wage becomes minor. Looking at wage and employment data for the U.S., I find that, if Acemoglu's model is taken seriously, a further increase in the relative supply will not lead to additional growth in the Gini-coefficient. Instead, wage inequality can be expected to fall in the course of continuing growth of the skilled work force.

\footnotetext{
${ }^{9}$ The values proposed by Acemoglu imply $\frac{w_{h}}{w_{l}}=c \cdot\left(\frac{H}{L}\right)^{0.06}$. For the simulation, I chose $c=1.7$ from the baseline estimation. Other values for $c$ yield very similar results.

${ }^{10}$ For the specifications with lags, I calculated the steady state relationship between $\frac{w_{h}}{w_{l}}$ and $\frac{H}{L}$ in order to display the Gini-coefficient in the two-dimensional Gini- $\frac{H}{L}$-space.

${ }^{11}$ This argument has also been used to promote subsidies to education.

${ }^{12}$ Education subsidies would then seem counterproductive for fighting wage inequality: “... subsidies to education lead to an increased tendency to acquire education, and also to a larger education premium due to the directed technology effect." Acemoglu (1998), p. 1078.
} 


\section{References}

Acemoglu, D. (1998): "Why Do New Technologies Complement Skills? Directed Technical Change and Wage Inequality," Quarterly Journal of Economics, 113, 1055-1090.

(2002a): "Technical Change, Inequality, and the Labor Market," Journal of Economic Literature, 40, 7-72.

(2002b): "Technical Change, Inquality, and the Labor Market," Journal of Economic Literature, XL(1), 7 - 72.

Berman, E., J. Bound, and S. Machin (1998): "Implications of Skill-Biased Technological Change: International Evidence," Quarterly Journal of Economics, pp. 1245-1279.

Gottschalk, P., and T. M. Smeeding (1997): "Cross National Comparison of Earnings and Income Inequality," Journal of Economic Literature, 35(2), 633-678.

Katz, L., and D. Autor (1999): "Changes in the Wage Structure and Earnings Inequality," in Handbook of Labor Economics, ed. by O. Ashenfelter, and D. Card, vol. 3, chap. 26, pp. 1643-1555. Elsevier, Amsterdam.

Kiley, M. T. (1999): "The Supply of Skilled Labour and Skill-Biased Technological Progress," The Economic Journal, 109(458), 708 - 724.

Murphy, K., and F. Welch (2001): "Wage Differentials in the 1990s: Is the Glass Half-Full or Half-Empty?," in The Causes and Consequences of Increasing Inequality, ed. by F. R. Welch, pp. 341 - 364. University of Chicago Press. 


\section{Discussion Paper Series}

Mannheim Research Institute for the Economics of Aging Universität Mannheim

To order copies, please direct your request to the author of the title in question.

\begin{tabular}{|c|c|c|c|}
\hline Nr. & Autoren & Titel & Jahr \\
\hline 86-05 & Lothar Essig & $\begin{array}{l}\text { Measures for savings and saving rates in the } \\
\text { German SAVE data set }\end{array}$ & 05 \\
\hline $87-05$ & $\begin{array}{l}\text { Felix Freyland ed. by } \\
\text { Axel Börsch-Supan }\end{array}$ & $\begin{array}{l}\text { Household Composition and Savings: An } \\
\text { Overview }\end{array}$ & 05 \\
\hline 88-05 & $\begin{array}{l}\text { Felix Freyland ed. by } \\
\text { Axel Börsch-Supan }\end{array}$ & $\begin{array}{l}\text { Household Composition and Savings: An } \\
\text { Empirical Analysis based on the German SOEP } \\
\text { Data }\end{array}$ & 05 \\
\hline $89-05$ & Hendrik Jürges & $\begin{array}{l}\text { Unemployment, restrospective error, and life } \\
\text { satisfaction }\end{array}$ & 05 \\
\hline $90-05$ & Hendrik Jürges & $\begin{array}{l}\text { Gender Ideology, Division of Housework, and the } \\
\text { Geographic Mobility Families }\end{array}$ & 05 \\
\hline $91-05$ & $\begin{array}{l}\text { Hendrik Jürges } \\
\text { Wolfram F. Richter } \\
\text { Kerstin Schneider }\end{array}$ & $\begin{array}{l}\text { Teacher quality and incentives - Theoretical and } \\
\text { empirical effects of standards on teacher quality }\end{array}$ & 05 \\
\hline $92-05$ & $\begin{array}{l}\text { Hendrik Jürges } \\
\text { Kerstin Schneider }\end{array}$ & $\begin{array}{l}\text { Dynamische Lohneffekte beruflicher } \\
\text { Weiterbildung - Eine Längsschnittanalyse mit } \\
\text { den Daten des SOEP }\end{array}$ & 05 \\
\hline 93-05 & Alexander Ludwig & $\begin{array}{l}\text { Moment estimation in Auerbach-Kotlikoff models: } \\
\text { How well do they match the data? }\end{array}$ & 05 \\
\hline $94-05$ & Alexander Ludwig & $\begin{array}{l}\text { Aging and Economic Growth: The Role of Factor } \\
\text { Markets and of Fundamental Pension Reforms }\end{array}$ & 05 \\
\hline $95-05$ & Melanie Lührmann & $\begin{array}{l}\text { Population Aging and the Demand for Goods \& } \\
\text { Services }\end{array}$ & 05 \\
\hline $96-05$ & $\begin{array}{l}\text { Jorge Gonzalez- } \\
\text { Chapela }\end{array}$ & On Measuring Convergence in the Use of Time & 05 \\
\hline $97-05$ & $\begin{array}{l}\text { Christina Benita } \\
\text { Wilke }\end{array}$ & $\begin{array}{l}\text { Rates of Return of the German PAYG System - } \\
\text { How they can be measured and how they will } \\
\text { develop }\end{array}$ & 05 \\
\hline 98-05 & Karsten Hank & $\begin{array}{l}\text { Spatial Proximity and Contacts between Elderly } \\
\text { Parents and Their Adult Children: A European } \\
\text { Comparison }\end{array}$ & 05 \\
\hline $99-05$ & Matthias Weiss & $\begin{array}{l}\text { On the Evolution of Wage Inequality in } \\
\text { Acemoglu's Model of Directed Technical Change }\end{array}$ & 05 \\
\hline
\end{tabular}

